\title{
EXPERIÊNCIAS DE SANEAMENTO NA CIDADE DE BUENOS AIRES: DOS PROJETOS DE PELLEGRINI A CONCLUSÃO DO PROJETO BATEMAN (1829-1905)
}

\author{
EXPERIENCES OF SANITATION IN THE CITY OF \\ BUENOS AIRES: PELLEGRINI PROJECTS OF PROJECT \\ COMPLETION OF BATEMAN (1829-1905)
}

Fabiano Quadros Rückert*

\begin{abstract}
Resumo: O objetivo do artigo consiste em reconstituir a história do saneamento da cidade de Buenos Aires no período entre 1829 e 1905. Dentro deste marco cronológico, o texto pretende abordar ações políticas especificamente direcionadas para o abastecimento de água e para a construção de uma rede de esgoto na cidade. $\mathrm{O}$ enfoque proposto implica no estudo das diferentes formas de envolvimento do Poder Público e do capital privado na implantação de projetos, obras e serviços de saneamento para Buenos Aires. O conteúdo do artigo está dividido em duas partes que representam importantes mudanças ocorridas na condução das políticas de saneamento da cidade: a primeira parte contempla o período de 1829 a 1880 , quando surgem os projetos de captação de água elaborados por Carlos Enrique Pellegrini, tendo a municipalidade e o governo provincial como os principais agentes políticos do saneamento de Buenos Aires; a segunda destaca o contexto da federalização da cidade, quando as obras são assumidas pelo governo federal e o embate entre o capital privado e o poder público torna-se mais intenso, ela estende-se de 1880 a 1905, ano de conclusão das obras de saneamento projetadas pelo engenheiro John Fredrick La Trobe Bateman.
\end{abstract}

Palavras-chave: História. Saneamento. Buenos Aires.

\footnotetext{
* Doutorando no Programa de Pós-Graduação em História da Universidade do Vale do Rio dos Sinos (UNISINOS). E-mail: fabianoqr@yahoo.com.br
} 


\begin{abstract}
The purpose of this paper is to reconstruct the history of sanitation in the city of Buenos Aires in the period between 1829 and 1905. Within this chronological milestone, the paper seeks to address political actions specifically directed towards the water supply and construction of a sewerage system in the city. The proposed approach involves the study of different forms of interation of government and of private capital in project implementation, construction and sanitation services to Buenos Aires. The content of the article is divided into two parts that represent important changes in the conduct of political reorganization of the city: the first part covers the period from 1829 to 1880, when projects arise catchment water produced by Carlos Enrique Pellegrini, having municipality and the provincial government as the main agents of sanitation of Buenos Aires, the second highlights the context of the federalization of the city, where the works are taken over by the federal government and the clash between private capital and government becomes more intense, it extends up from 1880 to 1905 , the year of completion of project of sanitation of engineer John Fredrick La Trobe Bateman.
\end{abstract}

Keywords: History. Sanitation. Buenos Aires.

\title{
BUENOS AIRES E OS PRIMÓRDIOS DO SANEAMENTO
}

De entre los elementos de vida necesarios a los habitantes de uma ciudad, poços hay que les preocupen más que el agua, porque siendo un principal agente de nutrición y de saneamiento, es a la vez vehículo natural de los alimentos, como lo es de toda clase de gérmenes y de deyecciones. ${ }^{1}$

No decorrer da primeira metade do século XIX, a população de Buenos Aires apresentou um expressivo crescimento demográfico. O aumento da população acompanhou a valorização do seu porto nas rotas de comércio internacional e foi influenciado pela concentração de poderes políticos e militares na cidade - concentração iniciada no período colonial e intensificada durante o processo de independência do Vice Reino do Rio da Prata. Foi neste contexto de crescimento demográfico e de fortalecimento econômico de Buenos Aires que surgiu na elite portenha o desejo de modernizar a cidade e de racionalizar o uso do espaço urbano pela intervenção da engenharia e da arquitetura.

Na obra Buenos Aires: Ciudad Moderna (1880-1910), Elisa Rodovanovic apresenta um interessante estudo sobre a urbanização de Buenos Aires focado no período de 1880 a 1910, nele, a autora explora as relações entre o desejo de modernidade compartilhado pela elite portenha e as grandes obras públicas 
promovidas na capital federal sob a influência da arquitetura europeia. ${ }^{2}$ O trabalho de Rodovanovic, apesar de conter um expressivo volume de informações sobre a expansão territorial de Buenos Aires e sobre os principais arquitetos e engenheiros que colaboraram na modernização desejada pela elite portenha, não contempla as questões referentes ao abastecimento de água e à rede de esgoto da cidade. A mesma lacuna pode ser encontrada no estudo de James Scobie, intitulado Buenos Aires, del centro a los bairros (1870-1910); Scobie focou sua pesquisa no crescimento da cidade explorando a importância das ferrovias, das linhas de bonde e do mercado imobiliário na configuração do espaço urbano. Nestes dois trabalhos, a ausência dos projetos e obras referentes ao saneamento não pode ser justificada pelo recorte cronológico, pois foi justamente nas décadas finais do século XIX, que o saneamento de Buenos Aires ganhou importância na agenda política e no cotidiano da sociedade local.

Identificar lacunas no conhecimento existente é uma parte do trabalho historiográfico, a outra parte, consiste em colaborar para a compreensão e o preenchimento destas lacunas. No caso específico da história do saneamento de Buenos Aires, penso que o tema deve ser abordado como um assunto político e ao mesmo tempo como uma questão de urbanismo: por um lado, o saneamento é político porque a oferta de água potável e o destino do esgoto demandam ações do governo nas suas diferentes esferas; por outro lado, ele é uma questão de urbanismo na medida em que envolve obras para tornar a cidade mais higiênica e mais saudável.

Diante das considerações introdutórias expostas acima, proponho pensarmos as experiências de saneamento de Buenos Aires a partir do governo de Bernardino Rivadavia e, mais especificamente, a partir do empréstimo obtido com a companhia inglesa Baring Brothers para a criação de um novo porto e para a instalação de obras sanitárias em Buenos Aires. A negociação deste empréstimo, apesar de inserida no projeto de expansão do comércio externo argentino, criou a possibilidade de atrair engenheiros europeus, dentre os quais estava o italiano Carlos Enrique Pellegrini - convidado para planejar o saneamento da cidade. ${ }^{3}$

Em 1828 Pellegrini desembarcou na Argentina em condições adversas: Rivadavia havia sido deposto do governo e o dinheiro emprestado pelos ingleses para os investimentos na urbanização já havia sido consumido. ${ }^{4}$ Mesmo sem encontrar o apoio político que esperava, Pellegrini elaborou um projeto para o abastecimento de água que foi submetido à apreciação de uma Comissão convocada pelo governo. Antes de Pellegrini, o engenheiro inglês Santiago Beavans havia sido contratado pelo governo para realizar trabalhos de captação de água no subsolo, mas a iniciativa de Beavans não foi produtiva. ${ }^{5}$ Rejeitando a opção de uso do lençol freático, Pellegrini propôs captar a água do Rio da Prata usando um sistema de elevação mecânica para abastecer um reservatório que seria de uso público. A proposta foi tecnicamente bem avaliada 
pela Comissão, porém, os aspectos financeiros receberam críticas e o projeto não foi executado. ${ }^{6}$

Pellegrini continuou apostando na viabilidade da captação de água do Rio da Prata e em 1850 aplicou sua ideia no Molino de São Francisco. Neste local, ele usou máquinas para bombear a água e elevá-la até o reservatório construído ao lado do prédio. O sistema de captação e elevação mecânica implantado no Molino de São Francisco comprovou a viabilidade técnica da distribuição das águas do Rio da Prata e provocou mudanças nos hábitos da população local que passou a consumir a água do reservatório do Molino, comprada e revendida em pipas pelos aguateros. ${ }^{7}$

Motivados pelo resultado positivo obtido nas obras no Molino de São Francisco, em 1852, Pelegrini e os proprietários do empreendimento, Juan Blumstein e Augusto La Roche, dirigiram-se ao governo com um projeto propondo investimentos particulares para o abastecimento de água da cidade de Buenos Aires. Em troca, eles solicitaram a concessão de um terreno público para a instalação da casa de máquinas, o direito de venda da água durante quinze anos e a isenção de impostos para importação das máquinas necessárias. ${ }^{8}$ As negociações não foram bem sucedidas, mas no plano técnico, Pellegrini inovou propondo o uso de uma rede de canos para distribuição da água captada.

Carlos Enrique Pellegrini fracassou nas suas tentativas de convencer o Poder Público da importância do abastecimento de água de Buenos Aires, mas depois dele, surgiram outros projetos de diversas procedências, alguns solicitados oficialmente pelo Poder Público, outros feitos sem uma solicitação oficial. O contexto político criado com a queda de Rosas e com a implantação do governo Urquiza também contribuiu para o crescente interesse por investimentos na urbanização de Buenos Aires. Adepto da valorização dos governos municipais, Urquiza providenciou ações para restituir a autonomia de Buenos Aires, tendo promulgado em 1854 a Ley Orgánica de la Municipalidad. Esta lei atribuía ao governo municipal diversas responsabilidades, dentre as quais, estavam o provimento de água para o abastecimento da população. Cabe ressaltar que, apesar de propor a execução de melhorias urbanas, a lei de 1854 não colocava o fornecimento de água como uma prioridade para as obras públicas. Neste sentido, Bordi de Raguci afirma que:

No obstante, la tecnificación del agua no figura como prioritária en el enunciado de las mejorias a llevarse a cabo y ni siquiera el abastecimento por surtidores públicos. El empedrado encabezaba la lista de las urgências urbanas, seguido por las calles, caminos, ferrocarriles, puentes, canales, paseos, mercados y teatros y luego el "agua potable". 9 
Em 1856, o abastecimento de água de Buenos Aires foi incluído nas negociações bancárias entre o governo provincial e a empresa Brage y Cia. A iniciativa do governo provincial fracassou e o contrato foi cancelado por um Decreto do dia 26 de fevereiro de 1857. As lideranças políticas da cidade e de diversos locais da Argentina concordavam com a necessidade de prover Buenos Aires de água potável, porém, elas discordavam dos procedimentos para suprir esta necessidade: algumas lideranças expressavam disposição em usar capitais particulares, outras compartilhavam da ideia de que a oferta da água deveria ser uma responsabilidade do governo e, neste caso, a participação de particulares, quando inevitável, deveria estar submetida aos interesses públicos.

Seguindo os adeptos da ideia de que a oferta da água era responsabilidade governamental, o Dr. Roque Pérez e o engenheiro John Coghlan, na condição de assessores da municipalidade de Buenos Aires, rejeitaram os projetos para captação de água, recebidos em 1857 e 1858 . A rejeição foi respaldada por uma Comisión Especial de la Municipalidad, sendo que esta emitiu em 17 de julho de 1859 um documento encerrando estudos e discussões que se estenderam por cerca de dois anos. Neste documento, os membros da Comisión expressavam sua posição a respeito dos investimentos para o abastecimento de água.

[...] la postura de una obra pública puesta baixo el domínio de la ciência y emprendida cono una obra destinada a la conveniencia común y por hombres que únicamente se propongan el bien público, no puede ser sometida a la especulación privada ni a cálculos mezquinos. ${ }^{10}$

O mesmo documento que rejeitou os projetos procedentes de particulares sugeriu a designação do engenheiro John Coghlan para realização de planos e orçamentos necessários para o abastecimento de água da cidade. A designação foi aceita e Coghlan passou a trabalhar nos estudos para o saneamento de Buenos Aires.

Terminada a década de 1850 , a discussão sobre a responsabilidade do governo na oferta da água potável havia avançado, mas, na prática, o abastecimento da população continuava dependendo da distribuição das pipas feita pelos aguateros, além deste serviço particular, também existiam poços ou aljibes em algumas residências. A precariedade das condições de abastecimento de água em Buenos Aires foi registrada por Julio Lacroze no seu Estudio sobre la distribuición de agua en las ciudades, deste documento, citamos a seguinte passagem:

La de aljibe se rejunta en azoteas que a causa de su poca declividad no pueden estar nunca bien limpias y son generalmente el receptáculo de una porción de inmundicias, a más esa agua que permanece estancada tanto tiempo 
(tres y cuatro meses) contrae todos los defectos de una mala agua: a causa misma de esa larga estagnación se desarrollan en su seno vegetaciones y una porción de animales, cuyos despojos contribuyen a darle un mal gusto y un olor nauseabundo insoportable. En el río, los mismos carros que la distribuyen la van a buscar al bajo entre dos muelles, donde el agua está en las peores condiciones que se puede imaginar, asoleada y sucia con los resíduos que se arrojan de la ciudad y de los buques, etc., algunas veces suele estar tan inmunda que no se puede beber. La de los pozos, ya he dicho es tan mala que no se emplea sino en los usos más groseros. ${ }^{11}$

Concentrando uma crescente população e desprovida de um sistema de abastecimento de água adequado para a sua demanda, a cidade tornou-se um ambiente favorável para a proliferação de doenças ligadas à contaminação hídrica. Em 1852 e 1856, ocorreram dois surtos de Febre Tifoide que atingiram a Paróquia do Socorro e áreas próximos do Retiro, posteriormente, em 1867, uma epidemia de Cólera causou vítimas em todas as partes da cidade provocando grande mortandade e alertando as autoridades públicas para necessidade de ações mais enérgicas. ${ }^{12}$

Quando o Cólera atingiu Buenos Aires, surgiram grupos voluntários como a Comisión filantrópica de la Parroquia Catedral al Sur, da qual faziam parte importantes figuras da sociedade portenha. O Poder Público também reagiu criando a Comisión de Aguas Corrientes que sob a liderança do engenheiro Nicolás Canale iniciou trabalhos emergenciais para ampliar a oferta de água, porém antes do término do ano de 1867, conflitos políticos provocaram a renúncia dos membros do governo municipal e os trabalhos da Comisión foram interrompidos.

As divergências entre as elites políticas argentinas prejudicaram os projetos e obras para o saneamento de Buenos Aires em diversos momentos do século XIX: durante o governo de Rosas a maior parte das receitas obtidas com as exportações foi consumida nas guerras; posteriormente, a situação jurídica criada no governo de Urquiza colocou a administração municipal de Buenos Aires em conflito com o legislativo da província, uma vez que, as duas instâncias discordavam sobre suas responsabilidades na gerência da cidade. Nessa mesma época, as divergências entre os autonomistas e federalistas estavam acirradas.

Enquanto as lideranças políticas discutiam suas divergências sobre as relações entre a província e o governo nacional, a epidemia de Cólera continuou se alastrando e fazendo muitas vítimas em Buenos Aires. Para conter a mortalidade da epidemia o governo provincial formou a Comisión de Aguas Corrientes, Cloacas y adoquinados, presidida por Emílio Castro e tendo John Coghlan no cargo de engenheiro chefe. Nesta iniciativa do governo 
provincial, cabe destacarmos que a intenção de providenciar o abastecimento de água estava acrescida da expectativa de uma solução para o problema do destino das cloacas - problema que ganhou relevância diante do impacto das epidemias. No dia 23 de dezembro de 1867, o legislativo provincial sancionou uma lei que autorizava ao Banco da Província a conceder um empréstimo para a municipalidade investir no saneamento de Buenos Aires.

Depois de analisar propostas de particulares apresentadas para a municipalidade, a Comisión de Aguas Corrientes, Cloacas y adoquinados emitiu parecer favorável ao projeto de abastecimento elaborado pelo próprio engenheiro John Coghlan. Recuperando-se dos efeitos da epidemia de Cólera e esperando obter na água potável uma proteção contra esta doença, as autoridades políticas aceleraram a execução das obras. No dia 20 de setembro de 1868, foi lançada a pedra fundamental da casa de máquinas, em 24 de dezembro do mesmo ano, ocorreu o primeiro teste das máquinas e, no dia 04 de abril de 1869, foi iniciado o fornecimento de água potável para a população. Em discurso realizado na solenidade da inauguração do serviço de abastecimento, o presidente Domingo Faustino Sarmiento relacionava a oferta da água com a conservação da saúde e a educação do povo.

Las gentes educadas se prodigan a si mismas las abluciones indispensables a la conservación de la salud, el pueblo, ignorante y provisto de agua abundante perseverará en sus hábitos de desaseo y intemperancia sy su estado moral y intelectual no se mejora. [El agua potable es] necesaria y excelente; pero si no damos educación al pueblo, abundante y sana, a manos llenas, la guerra civil devorará al Estado y el cólera a la población. ${ }^{13}$

A oferta de água abundante citada no discurso de Sarmiento foi modesta para a demanda que a cidade apresentava na época. As obras realizadas foram uma adaptação provisória do projeto original de Coghlan e consistiam no fornecimento gratuito de água potável para uma parte restrita da cidade através de "surtidores públicos" e de conexões em alguns prédios do governo. A água era captada no Rio da Prata, bombeada até os tanques e filtros, instalados na Recoleta e, depois de tratada, era distribuída para a população e usada pelas locomotivas da empresa Ferrocarril Oeste. A relação da Ferrocarril Oeste com as primeiras obras para o tratamento de água em Buenos Aires e o clima de combate ao Cólera foram salientados pela historiadora Olga Noemí Bordi de Ragucci na seguinte passagem do seu estudo:

En realidad, se había aprovechado la necesidad que tenía la Empresa del Ferrocarril Oeste de agua filtrada para el uso de sus locomotoras, en razón de que el agua salobre los pozos 
dañaba los canos de sus maquinas. Para ello, las cañerias se levaron desde la costa del río a la altura del Bajo de la Recoleta, hasta al Parque de Artilería, hoy Plaza Lavalle. De modo que este proyecto Coghlan fue como una imposición de emergência por parte del Gobierno da la Provincia frente a la desoladora situación dejada por el cólera y por tanto librado "en carácter provisional". ${ }^{14}$

Passada a euforia da inauguração, a Comisón logo se defrontou com problemas de ordem administrativa e financeira do novo serviço. Havia uma crescente demanda de instalações residenciais e apesar da aprovação da cobrança de uma tarifa específica para as instalações residenciais, os custos excederam as receitas e dificultaram a expansão da rede de canos. Surgiram críticas ao trabalho de Coghlan e reclamações sobre a qualidade do serviço de abastecimento de água foram publicadas na imprensa, situação que motivou uma nova intervenção do governo provincial através de uma lei aprovada no dia 26 de setembro de 1870. Nela, a Ferrocarril Oeste foi afastada da Comisión de Aguas Corrientes, Cloacas y adoquinados, uma nova presidência foi nomeada e definiu-se em linhas gerias as obrigações desse órgão público. Coghlan não foi afastado do seu cargo, contudo a sua permanência tornou-se inviável, uma vez que, as suas justificativas para os problemas técnicos e financeiros que o serviço enfrentava não foram consideradas. Em 17 de janeiro de 1871, ele renunciou ao cargo de engenheiro chefe. ${ }^{15}$

No ano de 1871, uma epidemia de febre amarela atingiu Buenos Aires com uma intensidade sem precedentes na história argentina. Os efeitos dessa epidemia no cotidiano da população, as iniciativas de civis e do Poder Público para conter a mortalidade foram temas abordados no trabalho de Miguel Angel Scenna na obra Cuando murió Buenos Aires - 1871, nela, o autor ressalta a precariedade do abastecimento de água existente na época.

Hasta ese momento la provisión de agua de la ciudad padecia de varias taras, a cual más peligrosa: podia ser comprada por unos centavos a los aguateros que la recogían del rio en los nunca lavados toneles com que la repartían por las calles. [...] El interior del tonel era un espléndido caldo de cultivo donde pululaban tranquilamente miríadas de ignorados gérmenes. El aguatero vendía al cliente esa agua desagradablemente turbia y éste debía decantarla y sacarle las larvas antes de usarla.

Algunas casas tenían aljibe, pozo de paredes impermiabilizadas donde se recogía el agua de lluvia. [...] Generalmente metiam dentro del mismo a una tortuga, que se alimentaba de larbas y bichos, manteniendo "limpo" el precioso líquido, al que se aportaba sus propias deyecciones. Finalmente, se podia obtener agua de pozo, indudablemente 
el médio más peligroso de todos, ya que se extraía de primeira napa, fatalmente contaminada. ${ }^{16}$

A epidemia de febre amarela, que atingiu Buenos Aires em 1871, foi pensada pelos médicos portenhos dentro de padrões científicos que vigoravam na época e apesar da existência de opiniões divergentes sobre formas de contágio e terapias adequadas, a relação entre a doença e a precariedade da higiene pública tornou-se um ponto comum no discurso dos médicos. Possivelmente, este discurso e o próprio ambiente de insegurança gerado pela epidemia, influenciaram nas ações do governo provincial que ordenou urgência na expansão da oferta de água potável e na construção da rede de esgoto que estava prevista nos estudos de Coghlan.

Segundo a determinação do Art. $3^{\circ}$ da lei que fixava suas diretrizes, a Comisión de Aguas Corrientes, Cloacas y adoquinados deveria consultar "ingenieros de reconocida competência", antes de proceder a realização das obras, esta determinação foi descumprida e os membros da Comisión consultaram um único engenheiro - seu nome era John Fredrick La Trobe Bateman. Na ocasião dos primeiros contatos, Bateman estava em Buenos Aires para apresentar seu projeto de modernização do porto da cidade e iniciou negociações com a Comisión. Ele havia realizado trabalhos de engenharia hidráulica de grande porte na Europa e possuía prestígio internacional, mas em contrapartida, seu projeto para o porto foi considerado inviável tecnicamente e demasiado caro, tendo recebido críticas de outros engenheiros. ${ }^{17}$

A concessão da coordenação das obras para um engenheiro que residia em Londres gerou protestos e denúncias de favorecimento pessoal. Apesar dos protestos e denúncias divulgados na imprensa, a Comisión encaminhou contratos com fornecedores europeus e solicitou ao governo um adiantamento financeiro para a execução de obras que ainda estavam sendo projetadas. A solicitação foi negada e a competência da Comisión para iniciar as compras foi questionada pelo poder executivo.

Em 1872, as críticas aos trabalhos conduzidos pela Comisión de Aguas Corrientes, Cloacas y adoquinados se intensificaram na imprensa e alguns políticos alertaram para necessidade de conter os excessos da Comisión. O interesse do governo nas obras de saneamento de Buenos Aires era inquestionável, mas não havia um consenso entre os legisladores sobre como encaminhar financeiramente a execução das obras. A falta de consenso tornouse evidente na sessão legislativa provincial de 20 de setembro de 1872, quando foram defendidas duas propostas: uma de autorização de um empréstimo no exterior e outra de liberação de um empréstimo de fundos públicos com títulos do Banco da Província. Depois de intensas discussões, a sessão encerrou-se sem produzir um acordo sobre o tema. No dia 23 de outubro, os legisladores reuniram-se novamente com o propósito de negociar uma solução e aprovaram 
a obtenção de um empréstimo estrangeiro, na mesma sessão, produziram um projeto de 22 artigos que limitavam a autonomia anteriormente concedida para a Comisión de Aguas Corrientes, Cloacas y adoquinados.

No ano de 1874, o advogado Emilio Bunge assume como novo presidente da Comisión e passa a trabalhar na revisão dos contratos firmados com Bateman. Bunge apontou erros nos procedimentos para aquisição de material na Europa, reprovou a excessiva autonomia com que o engenheiro Bateman conduzia os trabalhos residindo em Londres e criticou a atuação dos representantes de Bateman na Argentina. ${ }^{18}$

As críticas contra Bateman e seus representantes se intensificaram com o aumento dos pressupostos apresentados ao governo no contrato inicial e com a realização de trabalhos não previstos no projeto. Sem reservas financeiras disponíveis, em 1876, o Senado Provincial voltou a discutir a viabilidade de um novo empréstimo para concluir as obras. O senador Luis A. Huergo, membro da primeira turma de engenheiros formados na Argentina, ocupou um lugar destacado na plenária revisando a série de equívocos cometidos na condução dos assuntos referentes ao saneamento de Buenos Aires. Huergo também propôs um projeto de lei que fixava novas obrigações para este órgão, buscando interferir especialmente na questão dos pressupostos e da apresentação dos relatórios.

Quando o assunto foi apreciado na Câmara de Deputados da Província, surgiram denúncias dirigidas contra Bateman e seus representantes. Depois de discutir o polêmico assunto, o legislativo sancionou um novo empréstimo para socorrer as obras de saneamento, mas os recursos liberados em 1876, apenas protelaram a paralisação das obras, comunicada oficialmente em maio de 1877. A indesejada suspensão das obras, a constante falta de recursos financeiros e o difícil diálogo entre os representantes de Bateman formavam um quadro complexo e problemático, diante do qual Bunge renunciou ao cargo de presidente da Comisión.

De 1877 a 1880, as obras de saneamento de Buenos Aires permaneceram paralisadas, entretanto o tema continuou sendo discutido e as partes envolvidas no embate (a Comisión de Águas Corrientes - o engenheirso Bateman e os seus representantes - e o governo provincial) produziram diversos documentos expressando múltiplas leituras para os motivos e consequências da paralisação. ${ }^{19}$

\section{O SANEAMENTO DE BUENOS AIRES DEPOIS DA FEDERALIZAÇÃO (1880-1905)}

No ano de 1880, depois da violenta guerra civil entre os portenhos e o exército nacional, a federalização de Buenos Aires foi concluída e o governo federal assumiu as dívidas contraídas pela municipalidade para execução 
de obras públicas. ${ }^{20}$ Como consequência desse arranjo político, no dia 19 de dezembro de 1880, o Dr. Eduardo Wilde recebeu do governo federal a incumbência de coordenar uma comissão para concluir os trabalhos de saneamento de Buenos Aires - agora transformada em capital nacional. Para acelerar as obras, Wilde decidiu renovar o contrato com Bateman e no dia 05 de agosto de 1881, o engenheiro inglês tornou-se o Diretor de las Obras de Salubridad de Buenos Aires.

Em 1882, foi realizada a licitação para contratação de uma nova empresa para conclusão das obras que seriam estendidas até La Boca e Barracas - áreas que não estavam contempladas no projeto inicial. O vencedor dessa licitação foi o construtor italiano Antônio Devoto. A equipe de Devoto iniciou as escavações e a instalação dos canos da rede de cloacas e o engenheiro Bateman era o Diretor de las Obras de Salubridad, tendo sob o seu comando uma oficina de técnicos instalada em Buenos Aires que estava com a posse dos mapas e plantas do projeto, ele também era o responsável pela compra e conferência dos materiais na Europa. Nestas condições, Bateman continuava com poderes para interferir no andamento das obras e fez isso reprovando os ajustes que o construtor Devoto pretendia realizar no projeto.

A morosidade das obras e os seus custos exorbitantes foram registradas em diversas matérias que exploravam o assunto para criticar a submissão do governo ao capital estrangeiro. Junto com as críticas, os periódicos expressavam a preocupação com a saúde pública e listavam os inconvenientes que a população de Buenos Aires enfrentava convivendo com tantas escavações e obras incompletas.

Depois de sucessivas prorrogações, as obrigações contratuais da Comissión de Águas Corrientes com Bateman foram encerradas no dia 27 de maio de 1896. ${ }^{21}$ Completava-se um período de 15 anos ao longo dos quais ele recebeu, conforme previsto no primeiro contrato firmado em 1871, 7\% do valor total das obras. Essa relação entre o custo total e a remuneração de Bateman foi um dos pontos mais criticados, tanto na imprensa quanto nos debates do legislativo provincial. Os críticos interpretavam o não cumprimento dos pressupostos e a autonomia que Bateman possuía como comprador das máquinas e materiais importados da Europa como "provas" da sua intenção de lesar os cofres públicos e alguns estendiam esta intenção para os membros da Comisión de Aguas Corrientes, Cloacas y adoquinados.

O General Roca já havia concluído seu mandato como presidente, sendo sucedido no cargo por Juarez Celman. Com Celman na presidência e Eduardo Wilde no cargo de Ministro do Interior, ambos adeptos do liberalismo econômico, o governo abriu negociações para o arrendamiento das obras e serviços sanitários da capital federal - encaminhando uma ruptura com as ideias expressadas em 1859 pelo grupo liderado por Emílio Castro e John Coghlan. 
No decorrer das negociações de arrendamiento, diversos jornais alertaram para incoerência de entregar o serviço para uma empresa particular sem o conhecimento prévio do valor da taxa que seria repassada aos contribuintes para o uso da rede de esgotos. Sobre este aspecto do saneamento de Buenos Aires, cabe ressaltar que em 1886 a maior parte dos canos para o recolhimento do esgoto já estava instalada, porém, o governo ainda não havia decidido o valor da taxa que deveria ser pago pelos usuários da rede. Outro ponto tecnicamente importante, é que as conexões domiciliares foram iniciadas antes da transposição do Riachuelo (obra necessária para que o esgoto da cidade fosse lançado em um ponto mais distante do Rio da Prata), nessas condições, a morosidade na conclusão das Obras de Salubridad gerou diversos inconvenientes para população a de Buenos Aires, especialmente para os habitantes da parte mais baixa da cidade, ponto de acúmulo do esgoto que já estava sendo lançado na rede.

Assim como ocorreu na contratação de Bateman, o governo não considerou as preocupações e críticas da opinião pública e realizou uma licitação através da qual o poder executivo firmou contrato de arrendamiento com a empresa denominada Canevalli. Seguindo os procedimentos formais, o Contrato Canevalli foi encaminhado para apreciação do Congresso no dia 24 de maio de 1887. ${ }^{22}$ Objeto de discussões intensas nas duas casas do legislativo e assunto destacado na imprensa da época, o projeto de arrendamiento das Obras de Salubridad de Buenos Aires foi aprovado na forma da Lei n. 1992 de 09 de setembro de 1887. Segundo a decisão dos legisladores, o arrendamiento deveria ser precedido de uma nova licitação - decisão que anulava, ao menos, temporariamente, as negociações anteriores entre o poder executivo e a empresa Canevalli. No dia 21 de junho de 1888, foi firmado um novo contrato, desta vez entre o governo federal e Samuel B. Hale.

Logo após o recomeço das obras, os problemas apontados pela imprensa e pelos críticos do arrendamiento no Congresso tornaram-se realidade. O preço do serviço de instalação entre as residências e a rede de cloacas tornou-se motivo de conflitos entre o Poder Público e os investidores sócios de Hale. Com o Decreto de 17 de maio de 1877, o governo nomeou uma comissão para "dirigir y vigilar la construcción de las obras domiciliares." A intervenção gerou protestos e Samuel B. Hale sentiu-se prejudicado com um procedimento não previsto no contrato. Depois de manifestar sua insatisfação, em 1888, Hale transferiu a concessão de serviços para um grupo de banqueiros de Londres que firmou contrato com o nome de The Buenos Aires Water Supply and Drainage Company. Essa empresa reivindicou o controle sobre as obras de instalações domiciliares, mas, não obteve sucesso na sua reivindicação e ao mesmo tempo, foi criticada pela insuficiência na oferta de água potável.

Em 1889, o engenheiro Bateman voltou ao cargo de Diretor de las Obras de Salubridad e, respaldado pelo primeiro contrato com o governo, obteve o 
direito de receber pela fiscalização das instalações domiciliares que seriam realizadas. O retorno de Batemam e a incapacidade do Poder Público para reverter o rumo das negociações reforçaram a insatisfação dos proprietários de imóveis que aguardavam a demorada conclusão das obras. No final de 1889, importantes lideranças da cidade promoveram reuniões de proprietários de imóveis que reivindicavam a suspensão do contrato de arrendamiento. As lideranças decidiram radicalizar com um boicote no pagamento das taxas exigidas pelo governo para uso da rede de cloacas. Bordi de Ragucci destacou as consequências dessa mobilização social nos seguintes termos:

Es óbvio que todos estes trabajos tendían a lograr una resistencia "legal" y unânime al impuesto em oro y se logro; algunos depositaban en el respectivo juzgado y los más no ló pagarán. Así fue que la Empresa paso a la ofensiva y hacia fines de noviembre comezaron a cortar el servicio de agua en las casas de Município cuyos dueños no satisfacian el impuesto. En 9 de diciembre la Municipalidad dava a conocer una Ordenanza pela cual se prohíbia abrir los pavimentos de las calles y veredas para cortar los caños de conexión de água corriente de las casas cuyos os proprietários o inquilinos acrediten haber depositado el importe que impone la Empresa de las Obras, hasta tanto la autoridad se resuelva. ${ }^{23}$

A intervenção da municipalidade de Buenos Aires no jogo de forças entre a companhia inglesa e o grupo de habitantes envolvido no boicote do pagamento agravou as relações entre o Poder Público e os investidores que exigiam resolver a questão no âmbito federal. Quando o ano de 1890 começou, os problemas na gestão do saneamento de Buenos Aires ainda aguardavam soluções e colocavam-se como um grande desafio para todas as esferas do Poder Público. Neste ano, ocorreu uma importante mudança na liderança política do país: um novo governo assumiu a presidência e no cargo de Ministro do Interior estava Roca que havia expressado sua reprovação aos diversos arrendamientos feitos na gestão de Juarez Celman.

A partir de julho de 1890, a presidência nacional foi assumida por Carlos Pellegrini. ${ }^{24}$ Juntos, Pellegrini e Roca encaminharam uma série de procedimentos que resultaram na anulação do arrendamiento das Obras de Salubridad de Buenos Aires. A primeira ação do novo governo federal foi subordinar o saneamento de Buenos Aires ao Ministério de Obras Públicas - estratégia que permitiu neutralizar as interferências da Oficina Técnica de Bateman.

A intervenção do governo prosseguiu com nomeação do engenheiro Juan F. Sarhy para realização de inspeções nas obras que estavam em 
andamento. Essa iniciativa, apesar de não ser uma solução definitiva, anulava a autonomia com que a Oficina Técnica de Bateman conduzia os trabalhos das instalações domiciliares. Os interesses ingleses foram defendidos ao custo de duras críticas dirigidas à Comisión de Águas Corrientes e ao próprio engenheiro Sarhy e os banqueiros ingleses também expressaram sua preocupação com os investimentos feitos nas obras sanitárias de Buenos Aires. O andamento das discussões foi acompanhado pela imprensa que, como sabemos, apoiava a anulação do arrendamiento, opção que também passou a ser publicamente defendida pelo engenheiro Sarthy.

A decisão do impasse coube ao poder executivo e, mais especificamente, à Roca que respondia pelo Ministério do Interior e que havia viajado à Londres para tratar de assuntos referentes à dívida externa do país. Roca estava ciente de que a recisão do arrendamiento das obras sanitárias prejudicaria a credibilidade da Argentina, apesar disso, decidiu-se em favor do cancelamento do contrato com a The Buenos Aires Water Supply and Drainage Company e da suspensão definitiva dos trabalhos da Oficina Técnica Bateman. Em dezembro de 1890, o governo tornou pública a decisão e no ano seguinte encaminhou as formalidades necessárias para a sua execução. ${ }^{25}$ Com essa medida, ele buscou conter a crescente insatisfação dos proprietários de imóveis de Buenos Aires e, ao mesmo tempo, assumiu a responsabilidade pela conclusão do Sifão do Riachuelo - obra que permanecia como um reconhecido desafio para a engenharia da época.

A suspensão do contrato de arrendamiento das obras de saneamento da capital federal, apesar de ser um fato pontual na história do saneamento desta cidade, foi produto de um processo de expansão do aparelho estatal argentino. Desde o período de Rivadavia, o governo foi gradualmente qualificando os seus quadros técnicos e ampliou as suas ações em diferentes setores da economia. No decorrer deste processo, intensificado depois da federalização de Buenos Aires, o Ministério de Obras Públicas passou a exercer uma função especial na elaboração de projetos e estudos de interesse nacional e parte do seu trabalho foi dirigido para a ampliação das obras de saneamento de Buenos Aires.

No dia 29 de agosto de 1891, o governo federal promulgou a Lei n. 2796 e a partir dela iniciou uma ampla reformulação na gestão dos serviços sanitários na Argentina. Em 1894, mesmo sem a conclusão das obras previstas no projeto de Bateman, foi promulgada a Lei $\mathrm{n}^{\circ} .3856$, autorizando a expansão da rede de saneamento para outras áreas da cidade. Estender o saneamento para as periferias da planta urbana era uma condição para qualificar as condições de higiene das populações de baixa renda e, neste sentido, a medida encontrava respaldo no forte discurso higienista da época. ${ }^{26}$ No plano da engenharia, a extensão demandava novos projetos e novas construções e oferecia a oportunidade necessária para os técnicos do Ministério de Obras Públicas comprovarem suas habilidades profissionais. 
Em 1887, o Gran Depósito de Gravitación começou a ser construído em Buenos Aires; posteriormente, este prédio tornou-se popularmente conhecido como Palacio de las Aguas. O desenho da parte externa do prédio foi feito pelo arquiteto norueguês Olaf Boye e o material usado na sua construção foi importado da Europa. Produto exemplar da arquitetura do final do século XIX, o Palácio de las Aguas pode ser considerado o marco de uma nova fase nas obras de saneamento em Buenos Aires. Nesta nova fase, o problema da limitação dos recursos perdeu importância, as obras ganharam complexidade e as intervenções de Bateman - produzidas em parte pela inexperiência do governo na condução dos contratos - estavam superadas. Outra mudança importante foi o crescimento no número de profissionais de engenharia formados no país e a disposição do governo em incorporá-los aos seus quadros técnicos, sobretudo no setor de obras públicas.

No mesmo ano em que o Palácio de las Aguas começou a ser construído, os partidos de San José de Flores e de Belgrano foram incorporados à cidade de Buenos Aires. Com a incorporação, ampliava-se a demanda de água necessária para abastecer a população da capital federal. Em 1895, esta população havia excedido as estimativas previstas para o projeto de Bateman que ainda não estava concluído. ${ }^{27} \mathrm{Na}$ passagem do século XIX para o XX, o governo estava atacando o saneamento da capital em uma dupla frente de trabalho: (1) a conclusão das obras previstas por Bateman com os seus necessários ajustes técnicos, (2) a elaboração de novos projetos para a Buenos Aires do futuro. ${ }^{28}$

O conjunto das obras do projeto Bateman foi concluído em 1905 e a área atendida por ele passou a ser chamada de Antigo Radio. ${ }^{29}$ No conjunto destas obras, podemos destacar a antiga torre de captação no Rio da Prata, a casa de máquinas (atualmente sede do Museu Nacional de Belas Artes), a unidade de potabilização da Recoleta (desativada em 1936), o Palácio de las Aguas na Avenida Córdoba (sede do atual Museu de las Aguas) e o Sifão do Riachuelo. Não menos importante, apesar de ocultos, foram os milhares de canos estendidos pelo subsolo da cidade - marcas de uma Buenos Aires que materializou o seu desejo de modernidade e a sua intenção de ser uma cidade limpa e saudável.

\section{CONSIDERAÇÕES FINAIS: A DIMENSÃO SOCIOAMBIENTAL DO SANEAMENTO DE BUENOS AIRES (1829-1905)}

A construção deste artigo, intencionalmente, privilegiou a dinâmica das ações políticas que possibilitaram o saneamento de Buenos Aires dentro do marco cronológico fixado (1829-1905), porém no decorrer da pesquisa nas fontes documentais e no estudo da bibliografia, foi possível identificar outras possibilidades de abordagem do tema. Neste sentido, apresento algumas 
considerações sobre a dimensão socioambiental das experiências de saneamento de Buenos Aires contempladas ao longo do artigo.

Escrever sobre a dimensão socioambiental do saneamento significa pensar o impacto das obras de abastecimento de água e das redes de esgoto na saúde e no cotidiano dos habitantes de uma determinada cidade e, ao mesmo tempo, significa pensar as mudanças provocadas pelo saneamento no ecossistema ocupado pela cidade. No campo da Geografia, o conceito de morfologia urbana, parece dar conta desta dupla tarefa. ${ }^{30}$ Para os geógrafos, a morfologia urbana é fundamental no estudo das experiências de planejamento das cidades e na observação de como os fatores ambientais potencializam ou limitam as possibilidades de intervenção humana na construção do espaço urbano. Seguindo essa perspectiva, podemos afirmar que as obras de saneamento foram um importante elemento da morfologia urbana de Buenos Aires, tendo contribuído expressivamente para a integração das periferias ao centro da cidade.

Nas décadas finais do século XIX a capital argentina apresentou uma rápida ampliação do abastecimento de água e da rede de esgotos em direção às suas periferias. Na direção sul, cabe destacar a extensão das redes de cano na direção de Barracas e La Boca, decidida em 1882; na direção norte, o governo anexou o partido de Belgrano ao território da capital federal e expandiu as obras de saneamento naquela área, na mesma época, o partido de San José de Flores também foi anexado, ampliando o saneamento na parte sudoeste da cidade. Como consequência desta incorporação das periferias ao mapa do saneamento desenhado pelo Projeto Bateman, a cidade pode melhorar as precárias condições de vida da população pobre e pode diminuir os seus índices de mortalidade. As relações entre saneamento de Buenos Aires e a saúde da população foram destacadas por Antonio Brailovscky e Dina Foguelman nos seguintes termos:

[...] los registros de mortalidad en Buenos Aires eran altos, mayores de 30 por mil hasta 1871; fueron diminuyendo luego del tendido de la rede de agua potable, y cayeron a menos del 15 por mil cuando se añadio la instalación de desagües cloacales y pluviales en el radio antiguo, hacia 1890. Es decir, la mortalidad cayó a menos de la mitad en veinte años, pasó a ser una de las más bajas de América Latina, y equiparable a los valores de París, Londres, Madrid, y todas las ciudades europeas cuyas pautas culturales copiábamos. La disminución fue notable, sobre todo en enfermedades hídricas: la tifóidea casi desapareció como causa de mortalidad en Buenos Aires, con una tasa inferior al 2 por diez mil. ${ }^{31}$ 
Provida de água em abundância e de uma extensa rede de esgotos, Buenos Aires iniciou o século XX em condições de suportar o seu acentuado crescimento demográfico. Mas isso não significa dizer que as condições de salubridade do ambiente urbano fossem perfeitas. A poluição industrial era grande e os conventillos continuavam concentrando um numeroso contingente de pobres que formavam a base da crescente classe social operária portenha. ${ }^{32}$ Do ponto de vista econômico, a existência dos conventillos e a precariedade das condições higiênicas que estas habitações apresentavam podem ser consideradas consequências da industrialização e do processo de imigração europeia, todavia, ao lado desta interpretação, respaldada em diversos estudos, podemos também considerar os conventillos como um problema ambiental, uma vez que eles contribuíam para a concentração demográfica na área urbana de Buenos Aires e, frequentemente, eram focos de diferentes tipos de doença.

E o que podemos dizer sobre os impactos ambientais decorrentes do primeiro ciclo de saneamento de Buenos Aires? Esta questão excede aos objetivos do texto, mas considerando a sua importância, proponho apontar duas perspectivas que podem ser exploradas em novos estudos sobre o tema. Em primeiro lugar, as obras de saneamento ligaram diferentes pontos da cidade ao Rio da Prata, ponto de captação da água consumida pela população e, ao mesmo tempo, destino do esgoto doméstico e dos efluentes industriais gerados pela cidade. Com o sistema de captação no Rio da Prata e com a extensa rede de canos construída a partir do projeto Bateman, o abastecimento de água passou a seguir um fluxo inverso ao da topografia, ou seja, a água potável subia em direção as partes mais altas de Buenos Aires, podendo ser usada nas residências à quilômetros de distância do rio.

A ideia de que a Engenharia podia "domar as águas" ganhou impulso e o governo decidiu interferir no curso de arroios que cortavam o território da cidade para facilitar o transporte e evitar a estagnação das águas pluviais. Como consequência desta interferência da Engenharia e da política no curso natural das águas, as enchentes nas partes mais baixas de Buenos Aires tornaram-se um problema crônico da cidade. As enchentes representam um ônus ambiental difícil de ser mensurado, especialmente se considerarmos que, as áreas atingidas foram ocupadas pela população mais pobre da cidade. Chegamos então ao ponto de encontro entre os problemas ambientais e os problemas sociais - ponto em que encerramos este artigo sobre a história do saneamento de Buenos Aires na expectativa de que ele possa contribuir para novos estudos sobre a história das complexas relações entre o ser humano e as águas. 


\section{NOTAS}

1 CANDIOTI, Marcial R. Cincuentenario de las obras de la capital federal. 1868 - 1918. Buenos Aires: Obras Sanitárias de la Nación, 1921. p. 10.

2 RADOVANOVIC, Elisa. Buenos Aires. Ciudad Moderna (1880-1910). Buenos Aires: Ediciones Turisticas, 2002.

3 Sobre a iniciativa do governo de Bernardino Rivadavia para atrair engenheiros europeus para a Argentina, recomenda-se a consulta da obra de Enrique Daniel Silva, intitulada La Ingenieria. Su pasado y presente en nuestro país. San Justo: Universidad Nacional de la Matanza, 2009. Nesta obra, Silva descreve o contexto em que Pellegrini recebeu o convite para trabalhar no saneamento de Buenos Aires e relaciona este convite com o interesse do governo pela criação de uma instituição de ensino superior na área da engenharia.

${ }^{4}$ Ingeniero Carlos Enrique Pellegrini. Revista del Administración Nacional del Agua, Buenos Aires: Ministerio de Obras Públicas, n. 100, p. 290-293, 1945.

5 CONICET. Agua y saneamento en Buenos Aires. 1580-1830. Riqueza y singularidad de un patrimonio. Buenos Aires: Aguas Argentinas, 1999. p. 16.

${ }^{6}$ PRIGNANO, Ángelo O. Buenos Aires higiénica. Agua y cloacas: entre la realidad y la ficción. Buenos Aires: Ediciones CICCUS, 2010. p. 19.

7 HERZ, Enrique. Historia del agua en Buenos Aires. Cuadernos de Buenos Aires, Buenos Aires: Municipalidad de la Ciudad de Buenos Aires, n. 54, p. 73, 1979.

8 Proyecto preparado por el Ing. Carlos E. Pellegrini en el año 1829, para suministrar agua clarificada a la ciudad de Buenos Aires. In: Boletín de Obras Sanitarias de la Nación, n. 20, p. 132-136, febrero 1939.

9 BORDI DE RAGUCCI, Olga N. El agua privada en Buenos Aires (1856-1892). Negocio y fracaso. Buenos Aires: Editorial Vinciguerra, 1997. p. 27.

${ }^{10}$ Idem, p. 34.

${ }^{11}$ LACROZE, Julio. Estudio sobre la distribución de agua en las ciudades. Buenos Aires: Imprenta del Mercurio, 1866.

${ }^{12}$ RECALDE, Hector. Las epidemias de Colera (1856 - 1895). Buenos Aires: Ediciones Corregidor, 1993. p. 57.

${ }^{13}$ ARMUZ, Diego. La ciudad impura. Salud, tuberculosis y cultura en Buenos Aires, 18701950. Buenos Aires: Edhasa, 2007. p. 214.

${ }^{14}$ BORDI DE RAGUCCI, op. cit., p. 47.

${ }^{15}$ Memoria de la Comisión de Aguas Corrientes. In: Memoria de las Oficinas del Departamento de Hacienda de la Provincia de Buenos Aires. Buenos Aires: Imprenta de "La Prensa", 1871. p. $156-178$.

${ }^{16}$ SCENNA, Miguel Angel. Cuando murió Buenos Aires - 1871. Buenos Aires: Cântaro, 2009. p. 149 .

${ }^{17}$ El ingeniero Juan Frederico La Trobe Bateman. Boletín de Obras Sanitárias de la Nación. Buenos Aires: Ministerio de Obras Públicas, n. 44, p. 290 - 293, 1941.

${ }^{18}$ Memoria sobre las Obras de Salubrificación (1874 - 1876). Buenos Aires: Imprenta del Mercúrio, 1876. 
${ }^{19}$ Memoria de la Comisión de Aguas Corrientes, Cloacas y Adoquinado - Año 1879. Buenos Aires: Imprenta de la Penitenciaría, 1880.

${ }^{20}$ A federalização de Buenos Aires é um dos temas mais complexos da história argentina e diversos historiadores abordam este tema. Félix Luna, na obra Breve Historia de los Argentinos (Buenos Aires: Espejo, 1994) insere a federalização no processo de construção do Estado Nacional iniciado com a independência e interrompido em diversos momentos. Outra perspectiva pode ser encontrada na obra de José Luis Romero intitulada Las ideas políticas en la Argentina (Buenos Aires: Fondo de Cultura Economica, 2010), nela, o autor destaca a preocupação das elites com as contradições econômicas, sociais e demográficas configuradas entre Buenos Aires e o interior ao longo do século XIX. Segundo Romero, diante do agravamento das contradições regionais, a federalização de Buenos Aires foi interpretada por determinados grupos da elite como uma possibilidade de fortalecer a unidade do país. Cabe ainda destacar o estudo de Hilda Sabato (Buenos Aires en armas: La Revolución de 1880. Buenos Aires: Siglo XXI Editores, 2008) que aborda o conflito civil entre os portenhos e o governo nacional a partir de aspectos da cultura militar da época e das complexas alianças políticas que sustentavam o processo eleitoral.

${ }^{21}$ Memoria de la Comisíon de las Obras de Salubridad de la Capital - Año 1896. Buenos Aires: Taller Tipográfico de la Penitenciaría, 1897.

${ }^{22}$ Arrendamiento de las Obras de Salubridad de la Capital. Memoria del Ministerio del Interior - Año 1887-1888. Buenos Aires: Imprenta del "Sud América", p. 29-119.

${ }^{23}$ BORDI DE RAGUCCI, op. cit., p. 300.

${ }^{24}$ Carlos Pellegrini foi um dos quatro filhos nascidos do casamento do engenheiro Carlos Enrique Pellegrini com María Beavens Brigth.

${ }^{25}$ Uma interessante interpretação para a suspensão do arrendamiento das obras de saneamento da capital federal foi proposta por Antonio Elio Brailovsky e Dina Foguelman na obra Memória Verde: Historia ecológica de la Argentina. 10 ed. Buenos Aires: Debolsillo, 2011. Para estes autores, a sucessivas paralisações das obras estavam relacionadas à crise econômica internacional que se configurou na década final do século XIX; naquele contexto de crise, a suspensão do arrendamiento mediante uma indenização do governo argentino tornou-se interessante para os investidores da rede bancária Baring Brothers que usaram a paralisação das obras para pressionar a suspensão do contrato (p. 211).

${ }^{26}$ Sobre o discurso higienista construído na Argentina no final do século XIX e sua relação com as mudanças na cidade de Buenos Aires, a obra de Diego Armuz (2007) oferece alguns elementos iniciais para a compreensão do tema. O trabalho de Miguel Angel Scenna (2009) também aborda o assunto a partir dos efeitos da epidemia de Febre Amarela que atingiu Buenos Aires em 1871. Para um estudo geograficamente mais abrangente, recomenda-se a obra Higienismo, educación y discurso en la Argentina (1870 - 1940), organizada por María Silvia Di Liscia e Graciela Nélida Salto. Santa Rosa: Ed. de la Universidad de La Pampa, 2004.

${ }^{27}$ Memoria de la Comisíon de las Obras de Salubridad de la Capital - Año 1894. Buenos Aires: Imprenta de Martín Biedna, 1895.

${ }^{28}$ Dirección General de Obras de Salubridad de la Nación. Memoria presentada a S. E. el Señor Ministro de Obras Públicas por Guilhermo Villanueva, Director General. Buenos Aires: Imprenta de M. Biedma y hijo, 1903.

${ }^{29}$ Dirección General de Obras de Salubridad de la Nación - Año 1903-04-05. Memoria presentada a S. E. el Señor Ministro de Obras Públicas por Guilhermo Villanueva, Director 
General. Buenos Aires: Imprenta, litografia y encuadernación J. Peuser, 1906.

${ }^{30}$ Uma introdução ao conceito de morfologia urbana pode ser encontrada na Tese do geógrafo Paulo Roberto Rodrigues Soares, publicada no ano de 2000 com o título Del proyecto urbano a la produción del espacio: morfologia urbana de la ciudad de Pelotas, Brasil (1812-2000). Na terceira página da Tese, o autor destaca a polissemia de significados que o conceito comporta e afirma: "[...] el concepto de morfología urbana se refiere principalmente a los estudios de interpretación de los planos urbanos, de la edificación y de los usos del suelo como resultado de los 'procesos de crecimiento y remodelación de una ciudad a lo largo del tiempo." SOARES, Paulo Roberto Rodrigues. Del proyecto urbano a la producción del espacio: morfología urbana de la ciudad de Pelotas, Brasil (1812-2000). Tese (Doutorado em Geografia), Universidad de Barcelona, Barcelona, 2000, p. 3.

${ }^{31}$ BRAILOSVSKY, Antonio Elio; FOGUELMAN, Dina. Memoria Verde: Historia Ecológica de la Argentina. Buenos Aires: Debolsillo, 2011, p. 211.

${ }^{32}$ Segundo Brailovscky e Foguelman: "Los conventillos consistían en edifícios de unas 25 habitaciones de tres metros por cuatro que se extendían a ló largo de un patio común y se alquilaban a outras tantas familias. [...]. Había 1.770 conventillos en 1880, llegando a 2.835 en 1887, año en que albergaron a más de 116.000 personas, o sea el 26 por ciento de la población porteña. [...]. En 1892 la media era de 3,8 personas por pieza." BRAILOSVSKY; FOGUELMAN, op. cit., p. 200.

Artigo recebido em outubro de 2012. Aceito em junho de 2013. 